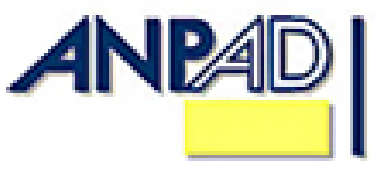
Disponível em
http://www.anpad.org.br/rac
RAC, Rio de Janeiro, v. 19, $2^{\text {a }}$ Edição Especial, art. 5, pp. 197-220, Agosto 2015 http://dx.doi.org/10.1590/1982-7849rac20151740
$(c)$ EY

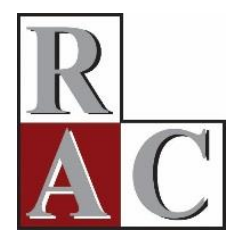

\title{
A Contribuição da Produção Científica em Marketing para as Ciências Sociais
}

The Contribution of Scientific Production in Marketing for the Social Sciences

Renato Hübner Barcelos Universidade Federal do Rio Grande do Sul - UFRGS

Carlos Alberto Vargas Rossi

Universidade Federal do Rio Grande do Sul - UFRGS

Artigo recebido em 14.11.2013. Última versão recebida em 03.08.2014. Aprovado em 13.08.2014. 


\title{
Resumo
}

Os pesquisadores de Marketing frequentemente empregam análises bibliométricas para avaliar a sua produção científica, porém poucos estudos examinam a influência que esta tem exercido fora da própria disciplina, isto é, nas ciências sociais com as quais ela mantém relação de interdisciplinaridade. Este estudo buscou suprir esse gap de conhecimento, analisando as citações recebidas pelos onze principais periódicos de Marketing nos top journals das ciências sociais mais próximas - Administração, Economia e Finanças, Psicologia, Sociologia e Antropologia - e identificando artigos, periódicos e temas de Marketing que mais têm tido impacto nessas áreas. Os temas foram construídos por meio do agrupamento das palavras-chave nos artigos, e os resultados foram interpretados por meio de análises de redes e de tabulação cruzada, identificando que, apesar de a contribuição geral da disciplina ser pequena, certos tópicos têm sido objetos de interesse de cada ciência social. Além disso, a contribuição externa da disciplina é polarizada, suprindo a Administração com metodologia e artigos de natureza gerencial e estratégica, e as demais áreas, principalmente com Comportamento do Consumidor. A partir dos insights obtidos, discute-se o status científico da produção de Marketing e os caminhos para a maior relevância da disciplina.

Palavras-chave: marketing; citações; análise bibliométrica; produção científica.

\begin{abstract}
Marketing researchers often employ bibliometric analysis to assess the importance of scientific production in the field, but few studies have examined its influence outside the discipline itself, particularly in the social sciences with which it maintains an interdisciplinary relationship. This study aimed to fill this knowledge gap by analyzing citations of the eleven leading Marketing journals in the top journals of the closest social sciences - Management, Economy and Finance, Psychology, Sociology and Anthropology - and identifying the articles, journals and subjects which have had more impact in these areas. The subjects were constructed by clustering article keywords, and the results were interpreted by means of network analysis and cross-tabulation. The results show that, although the overall contribution of the discipline is relatively small, certain topics have been objects of interest in each social science. Furthermore, the discipline's contribution is polarized, providing Management with methodology and articles of managerial and strategic natures, while providing other areas mainly with articles in Consumer Behavior. Based on the insights obtained, the scientific status of Marketing production is discussed, as well as the avenues for increasing the relevance of the discipline.
\end{abstract}

Key words: marketing; citations; bibliometric analysis; scientific production. 


\section{Introdução}

Qual tem sido a contribuição da produção científica de Marketing para as outras áreas? A importância de responder essa questão pode ser examinada sob dois aspectos. Em primeiro lugar, o Marketing nunca foi uma ciência isolada, mas sim uma área cujo crescimento se deveu em grande parte à sua interdisciplinaridade com a Administração, a Economia e outras ciências. Por isso, a capacidade do Marketing de contribuir com conhecimentos novos para as demais áreas pode ser vista tanto como um sinal de maturação quanto de retribuição científica, ao se mostrar capaz de produzir conhecimentos considerados úteis para as ciências que lhe deram base. Em segundo lugar, qualquer ciência se enriquece através da troca entre as redes de pesquisadores de diferentes áreas e, adquirindo maior status científico na medida em que sua base de conhecimento é amplamente difundida e usada por outras disciplinas e outros pesquisadores (P. F. Anderson, 1983). O reconhecimento de relevância da disciplina dentro de um espectro como o das ciências sociais integra o conjunto de aspectos que determinam a sua estatura teórica e, por conseguinte, científica. A interdisciplinaridade ajuda as disciplinas vizinhas a encontrarem respostas para problemas de pesquisa que, por vezes, transcendem as fronteiras teóricas e metodológicas de um determinado campo. Neste sentido, a importação e a exportação de conhecimento tornam-se rotas usuais de pesquisa.

Para o Marketing, esse conhecimento sobre seu potencial exportador de conhecimento pode converter-se em promissor recurso de autoanálise, com vistas à geração futura de conhecimento. Uma balança comercial de conhecimento francamente deficitária pode indicar, por um lado, que o caráter científico da disciplina se encontra em um nível ainda baixo, requerendo avanços substantivos; por outro, evidencia a oportunidade de desenvolver mais o corpo teórico da disciplina.

Além disso, a relevância do status de Marketing como ciência social perante as demais áreas é um caminho para atestar se a disciplina vem sendo valorizada para a sociedade como um todo, isto é, servindo tanto gerencialmente às empresas quanto promovendo bem-estar e qualidade de vida aos consumidores (Webster \& Lusch, 2013). Essa preocupação adquire importância no contexto em que acadêmicos chamam atenção para o declínio da influência de Marketing entre as ciências administrativas (Clark, Key, Hodis, \& Rajaratnam, 2014), assim como para as empresas e as ações governamentais (Day \& Montgomery, 1999; Reibstein, Day, \& Wind, 2009; Webster \& Lusch, 2013). Neste sentido, um autoexame crítico da utilidade da produção de Marketing é um ponto de partida para diagnosticar as razões desses problemas.

De fato, os pesquisadores de Marketing frequentemente lançaram olhares sobre sua própria produção, através de análises bibliométricas. Estudos recentes foram realizados buscando examinar os tópicos e artigos mais proeminentes em temas específicos relacionados à disciplina, como Comportamento do Consumidor (Baumgartner, 2010), Marketing Business-to-Business (Backhaus, Lügger, \& Koch, 2011), Propaganda na Internet (Kim \& McMillan, 2008) e Cocriação (Dalli \& Galvagno, 2013). Além disso, Davis, Golicic, Boerstler, Choi e Oh (2013) investigaram a produção dos principais periódicos de Marketing para verificar a evolução dos métodos mais utilizados pela disciplina, enquanto Talukdar, Hariharan e Boo (2011) realizaram uma análise voltada à concentração da produção de artigos em autores de Marketing. No contexto nacional, Mazzon e Hernandez (2013) procederam um levantamento da produção brasileira de Marketing ao longo de uma década, ao passo que Pinto e Lara (2007) fizeram uma investigação semelhante, focada na produção brasileira de Comportamento do Consumidor.

Uma das formas mais comuns de análise bibliométrica é a análise de citações, que é bastante adequada para a verificação da contribuição de um determinado autor, artigo ou periódico, ou mesmo de uma determinada área, na medida em que toma como indicador de impacto de uma produção científica a sua citação em outros trabalhos (Baumgartner, 2010; M. H. Anderson, 2006; Pieters \& Baumgartner, 2002). Análises de citações já foram usadas no Marketing para avaliar o impacto de autores em um determinado tema (Leone, Robinson, Bragge, \& Somervuori, 2011), comparar a influência estrutural de diversos periódicos entre si (Baumgartner \& Pieters, 2003) ou, em combinação 
com outras técnicas, para identificar quais fatores estão associados com um maior número de citações de um artigo (Stremersch, Verniers, \& Verhoef, 2007).

Neste sentido, um ponto em comum dos estudos bibliométricos já citados, assim como de diversos outros trabalhos (Castilhos, 2007; Faria, Oliveira, Lacerda, \& Lara, 2006; Rossi, 2008; Tellis, Chandy, \& Ackerman, 1999) é o foco na repercussão da produção dentro da própria disciplina, isto é, avaliando o impacto de temas, autores e artigos dentro dos limites dos periódicos de Marketing. Entretanto, uma busca na literatura revela que são poucos os estudos que têm buscado avaliar o que é efetivamente citado e que contribui para fora da disciplina de Marketing. Entre estes, encontram-se os dois trabalhos de Cote, Leong e Cote (1991, 1992), verificando, no primeiro estudo, as citações recebidas pelo Journal of Marketing e pelo Journal of Marketing Research, tanto no próprio Marketing quanto em outras ciências sociais; e, no segundo estudo, a contribuição do Journal of Consumer Research. Apesar do grande levantamento realizado pelos autores, em ambos os casos, a análise limitou-se ao impacto dos três periódicos focados, não contemplando, assim, o impacto da disciplina de uma forma geral, ou dos diferentes temas existentes dentro dela. Além disso, Pieters e Baumgartner (2002) fizeram uma análise focada na inter-relação dos periódicos de Economia com as outras áreas que, apesar de não focar nos detalhes da produção de Marketing, indicou que, de uma forma geral, esta área vem aproveitando muito mais os artigos da Economia do que o inverso.

Desta forma, o presente estudo tem como objetivo realizar uma investigação da produção de Marketing por meio de uma análise de citações, focando nas ciências sociais mais próximas, isto é, aquelas com maior importância no desenvolvimento da disciplina (Administração, Comunicação, Psicologia, Economia, Finanças, Sociologia e Antropologia) e buscando contemplar três níveis de análise: os artigos, os periódicos e os temas de Marketing (construídos a partir das palavras-chave). Cabe destacar que, embora análises bibliométricas envolvendo a identificação de periódicos e artigos sejam frequentes, análises envolvendo as palavras-chave são relativamente raras, pois envolvem procedimentos bastante onerosos de coleta e depuração - os trabalhos de Kevork e Vrechopoulos (2009) e Mela, Roos e Deng (2013) são alguns casos excepcionais de análises em Marketing focadas em palavras-chave. Neste estudo, a coleta e a categorização das palavras-chave foram essenciais para a identificação dos temas mais influentes em outras ciências, fornecendo um cenário mais rico da contribuição do Marketing do que apenas os outros níveis poderiam fornecer isoladamente.

Na próxima seção, são discutidos os procedimentos metodológicos de coleta e processamento dos dados dos artigos, assim como o recorte dos periódicos analisados e as técnicas auxiliares empregadas na análise das citações, como a análise de redes e a análise de tabulação cruzada. Na sequência, são apresentados os resultados, identificando os diferentes temas que mais contribuem para cada ciência, assim como alguns insights da natureza dessa contribuição. Por fim, os resultados são discutidos, oferecendo implicações sobre o desenvolvimento da produção e o status científico do Marketing perante as demais ciências.

\section{Método}

Esta análise da contribuição da produção de Marketing para outras ciências sociais foi realizada a partir de uma amostragem das publicações de periódicos selecionados de cada área. A seleção destas ocorreu a partir da proximidade que cada uma possui com o Marketing. As áreas de Administração e Comunicação podem ser consideradas as mais próximas, sendo, a primeira, a área de conhecimento na qual está vinculada a maior parte dos cursos de Marketing em todo o mundo, e, a segunda, uma área em que cada vez mais disciplinas de Marketing são incluídas nos currículos. Na sequência, encontram-se as áreas de Economia e Finanças, sendo a primeira a ciência-mãe do Marketing, e, a segunda, uma área fronteiriça entre a Administração e a Economia (Bartels, 1988; Baumgartner \& Pieters, 2003). Por fim, vêm as áreas de Psicologia, Sociologia e Antropologia, consideradas ciências mais puras, cuja influência tem se dado principalmente no entendimento do comportamento dos consumidores (Wilkie \& Moore, 2003). 
Para a seleção dos principais periódicos, foi utilizado o fator de impacto de cinco anos, do Journal of Citation Reports. O fator de impacto de cinco anos pode ser considerado mais adequado para a análise da influência de longo prazo de determinado periódico que o fator de impacto simples, por ser menos influenciado por aspectos de inflacionamento, como edições especiais, estratégias de autorreferência ou artigos de influência acima da média. A decisão de selecionar os periódicos com maior fator de impacto em cada área se justifica pelo fato de ser possível, assim, verificar a contribuição de Marketing nos periódicos de maior representatividade e visibilidade nas demais áreas. Foram então selecionados os cinco periódicos com maior fator de impacto de cada ciência social e, dentro de cada periódico, todos os números e volumes durante um período de quase seis anos (de 2006 a 2011), a fim de dar conta das possíveis oscilações de citações de Marketing nos periódicos.

Assim, na área de Administração, foram selecionados os periódicos (com o respectivo fator de impacto de cinco anos): Academy of Management Review (9,531), Academy of Management Journal (9,263), MIS Quarterly $(9,208)$, Strategic Management Journal $(6,931)$ e Administrative Science Quarterly $(6,216)$. Os periódicos de comunicação selecionados foram: Public Opinion Quarterly $(3,301)$, Journal of Communication (2,765), Human Communication Research $(2,482)$, Cyberpsychology, Behavior and Social Networking $(2,472)$ e Journal of Health Communication $(2,434)$.

Nas áreas de Economia e Finanças, os periódicos selecionados foram os mesmos, em função da associação entre as disciplinas no Journal of Citation Reports: Journal of Economic Literature $(8,922)$, Quarterly Journal of Economics $(8,171)$, Journal of Political Economy $(6,924)$, Journal of Finance $(6,536)$ e Journal of Financial Economics $(5,675)$. Em decorrência dessa associação, as áreas de Economia e Finanças foram consideradas em uma mesma categoria para as análises.

Para a Psicologia, o Journal of Citation Reports apresenta listagens de Psicologia Aplicada, Psicologia Experimental, Psicologia Multidisciplinar e Psicologia Social. Essas subáreas foram consideradas em conjunto, resultando na seguinte listagem: Annual Review of Psychology $(21,025)$, Psychological Bulletin (19,160), Trends in Cognitive Sciences (15,591), Psychological Review $(11,582)$ e Advances in Experimental Social Psychology (10,733).

Para a Sociologia, foram selecionados os periódicos: Annual Review of Sociology $(5,953)$, American Sociological Review $(5,578)$, American Journal of Sociology $(5,411)$, Sociological Methods and Research $(3,596)$, Social Networks $(3,328)$ e Journal of Marriage and Family $(2,957)$. O periódico Social Networks também consta na listagem da Antropologia, na qual também entraram: Journal of Human Evolution (4,077), Evolutionary Anthropology (3,864), Annual Review of Anthropology $(3,559)$ e Current Anthropology (3,113). Durante a coleta de dados, entretanto, verificou-se um número muito reduzido de citações a artigos de Marketing nesses periódicos, sendo todas provenientes apenas do Social Networks, que consta também na lista de Sociologia. Por essa razão, optou-se por agrupar as áreas de Sociologia e Antropologia em uma única categoria para as análises.

Para determinar os principais periódicos de Marketing, adotaram-se os mesmos critérios utilizados para as demais áreas, porém abrangendo um número maior de periódicos, uma vez que ela correspondia ao foco principal de investigação. Tendo em vista que o Journal of Citations Reports não apresenta uma classificação única de Marketing, foram selecionadas as dez principais publicações da área presentes na classificação de Negócios, ou seja: Journal of Marketing $(8,520)$, Journal of Retailing $(5,181)$, Journal of Consumer Research $(5,030)$, Journal of Marketing Research (4,768), Journal of Consumer Psychology $(4,559)$, Marketing Science $(4,251)$, Journal of Interactive Marketing $(4,021)$, Journal of Service Research $(3,973)$, Journal of Consumer Affairs $(2,168)$ e Journal of Public Policy \& Marketing $(2,157)$.

Após a seleção dos periódicos, procedeu-se à busca de citações a artigos de Marketing. Em cada um dos periódicos das outras áreas, durante o período estabelecido (2006-2011), foi feito o download de todos os artigos que citavam periódicos de Marketing, e as seguintes informações de cada artigo foram extraídas e registradas em uma base de dados em formato Excel: área, título, ano, volume e número do periódico; título e autores do artigo que faz a citação de Marketing; autores, ano, título do artigo e do periódico citado. O banco de dados assim obtido compreendeu 1314 artigos citados de 
Marketing e 619 artigos de outras áreas. Nesta contagem, foi excluído um artigo do Annual Review of Psychology que revisava a literatura de Comportamento do Consumidor e citava nada menos que 224 artigos de Marketing, sendo, portanto, um dado atípico que poderia causar vieses nas análises.

Ainda na coleta de dados, procedeu-se à busca das palavras-chave dos 1.314 artigos do banco de dados, que serviriam para informar os temas tratados por cada um. Como o excesso de variabilidade na elaboração das palavras-chave informadas pelos próprios autores poderia complicar excessivamente as análises, optou-se por utilizar os subject terms informados para cada artigo na base Business Source Complete do indexador EBSCO, que correspondem a um conjunto mais ou menos uniformizado de assuntos. Esse procedimento permitiu reduzir parcialmente a variabilidade de palavras-chave, embora o conjunto total obtido de 3006 subject terms diferentes ainda fosse extenso (cada artigo possuía, na média, 9,2 subject terms).

Dessa forma, os subject terms dos artigos tiveram de ser tratadas a fim de permitir as análises. Inicialmente, as 1.211 palavras-chave de menor frequência na base foram eliminadas pois representavam, em conjunto, menos de $10 \%$ do total das citações. Na sequência, foi adotado um procedimento em duas etapas, semelhante ao empregado por Mela et al. (2013): primeiro, os termos com significado ou contexto muito próximos foram combinados em uma mesma categoria; segundo, as categorias restantes foram combinadas entre si por meio de uma análise de clusters. A fim de reduzir a subjetividade da primeira etapa desse processo, as combinações foram feitas pelas avaliações de três pesquisadores, que discutiram entre si a semelhança dos termos e a possibilidade de associação em categorias. Dessa etapa, resultaram 78 categorias presentes nas seis áreas (Marketing, Administração, Comunicação, Economia \& Finanças, Sociologia \& Antropologia). Na etapa seguinte, as categorias de Marketing foram agrupadas em função das citações pelas categorias das demais áreas, usando-se análises de clusters do tipo K-Means e do tipo clusterização hierárquica (método de Ward). Para essas clusterizações, foi montada uma matriz em que cada linha representava uma das 78 categorias em Marketing e cada coluna, uma dessas categorias em cada uma das outras áreas, seguindo o procedimento também adotado por Mela et al. (2013). Nessa matriz, o valor de cada célula consistiu, assim, no número de citações de uma determinada categoria em Marketing (linha) por uma determinada categoria em outra área (coluna). Para as análises de clusters, as colunas foram empregadas como variáveis, sendo os casos rotulados pelas categorias em Marketing. O resultado das duas formas de clusterização foi semelhante e resultou em 15 clusters significativamente distintos entre si. A lógica deste processo foi a de agrupar as categorias de Marketing conforme elas fossem citadas de maneira semelhante, em quantidade e proporção, pelas mesmas categorias nas demais áreas. Os nomes dos clusters foram definidos pelas categorias com mais citações dentro de cada cluster, correspondendo, assim, aos principais temas.

Cabe destacar que o procedimento adotado ajudou a eliminar parte da subjetividade quanto ao que poderia ser considerado um tema ou não de Marketing, uma vez que, para os objetivos deste trabalho, interessava principalmente distinguir os temas conforme a diferença de contribuição para as ciências sociais abordadas. Cada artigo na base de dados poderia estar associado a vários temas ao mesmo tempo, conforme a conversão das palavras-chave originais para os temas finais da clusterização.

A base de dados final obtida consistiu, assim, em conjunto de díades (ou citações), cada uma englobando um artigo de uma ciência social e um artigo de Marketing citado, totalizando, assim, 2.214 citações. Além disso, como cada artigo está associado a um conjunto de palavras-chave, cada citação individual representa, por sua vez, um conjunto de díades de palavras-chave, o que leva o tamanho total da base a ser multiplicado quando o nível de análise a ser examinado é o tema, e não o artigo citado. Ocorrências repetidas de temas em uma mesma citação - isto é, quando mais de uma palavra-chave foi agrupada em um mesmo tema após o processo de categorização e clusterização mencionado - foram mantidas a fim de refletir a força de associação de um tema em um artigo e a força de contribuição de um tema de Marketing para uma área que tenha feito a citação em uma díade. Com isso, quando a unidade de análise é o tema, a base de dados total consiste em uma rede de mais de 160 mil registros, ligando temas de Marketing com temas em outras áreas. Um benefício dessa forma de categorização foi a de poder contar a produção conjunta de um tema através de vários artigos, sem necessidade de categorizar cada artigo de forma exclusiva em uma área separada, o que poderia causar vieses na quantificação dos resultados. 
Em relação às técnicas auxiliares de análise, primeiramente foram empregadas análises de tabulação cruzada e testes de qui-quadrado através do software SPSS v.20 para identificar diferenças significativas de contribuição dos temas ou dos periódicos para cada área. Na sequência, foram aplicadas análises de redes com geração de grafos por meio do Network Overview Discovery and Exploration add-in for Excel (NodeXL), um plug-in para o Microsoft Office Excel que permite a exploração visual de redes com diferentes algoritmos e opções de personalização. Os grafos das redes foram gerados a partir dos algoritmos Harel-Koren Fast Multiscale e Fruchterman-Reingold, que modelam os vértices (por exemplo, os temas neste estudo) como objetos que exercem forças físicas de atração e repulsão uns sobre os outros, dependendo das suas conexões. Cada conexão representa uma associação de citação entre temas, de modo que os temas mais frequentemente citados tendem a ficar mais próximos das fontes das citações, e, os menos citados, mais distantes nos grafos. Assim, os grafos permitem representar visualmente a força de contribuição de um tema em relação aos demais. Essas técnicas, juntamente com a apresentação das tabelas descritivas de resultados para cada nível de análise, permitem apresentar um conjunto mais completo de insights sobre a contribuição da produção de Marketing para as ciências sociais.

\section{Análise dos Resultados}

Os principais resultados da coleta de citações e da aplicação das técnicas de análise são apresentados a seguir, organizados conforme o nível de análise: em primeiro lugar, a contribuição de Marketing é examinada a partir das citações aos artigos; em segundo, a partir das citações aos temas; e em terceiro, a partir das citações aos periódicos de Marketing.

\section{Indicadores da contribuição de artigos de Marketing}

A Tabela 1 apresenta os dados gerais de citações de artigos de Marketing pelas ciências sociais. Como esperado, a área de Administração é a maior responsável pelas citações ao Marketing $(65,1 \%$ das citações), enquanto a Comunicação vem em segundo lugar (22,7\% das citações) e o volume de citações das demais áreas é bem menor. Chama a atenção, porém, que os periódicos da Psicologia fazem mais que o dobro de citações de referências a artigos de Marketing que os da Economia, ciência à qual o Marketing deve grande parte de sua formação (Bartels, 1988). Ao todo, apenas 28 artigos em top journals de Economia e Finanças e 27 artigos em Sociologia e Antropologia fizeram citações aos principais periódicos de Marketing no período estudado, indicando a contribuição bastante reduzida do Marketing para todas essas áreas, indo ao encontro das percepções de Baumgartner e Pieters (2003).

Tabela 1

Citações a Artigos de Marketing nos Top Journals de Ciências Sociais, em 2006-2011

\begin{tabular}{|c|c|c|c|c|c|}
\hline \multirow[t]{2}{*}{ Área } & \multirow{2}{*}{$\begin{array}{l}\text { Artigos com } \\
\text { referências a } \\
\text { Marketing }\end{array}$} & \multicolumn{2}{|c|}{ Artigos de Marketing citados } & \multicolumn{2}{|c|}{ Citações a artigos de Marketing } \\
\hline & & $\mathrm{N}$ & $\begin{array}{l}\text { Idade média } \\
\quad \text { (anos) }\end{array}$ & $\mathrm{N}$ & $\%$ \\
\hline Administração & 369 & 863 & 14,4 & 1441 & 65,1 \\
\hline Comunicação & 147 & 376 & 14,8 & 503 & 22,7 \\
\hline Psicologia & 48 & 142 & 8,4 & 162 & 7,3 \\
\hline Economia e Finanças & 28 & 62 & 14,9 & 66 & 3,0 \\
\hline Sociologia e Antropologia & 27 & 36 & 15,9 & 42 & 1,9 \\
\hline Total & 619 & 1314 & 14,1 & 2214 & 100 \\
\hline
\end{tabular}


Conforme a Tabela 1, a idade média das citações de Marketing é de 14,1 anos no momento da publicação dos artigos das demais áreas, um padrão relativamente idêntico em todas as ciências sociais abordadas, à exceção da Psicologia. Nota-se que esta área vem citando artigos relativamente recentes de Marketing (8,4 anos de idade, na média). Além disso, mais de 50\% das citações de artigos de Marketing nos top journals de Psicologia possuem até cinco anos de idade no momento da publicação, indicando que as contribuições do Marketing se difundem muito mais rapidamente nesta área do que nas demais.

A Tabela 2 apresenta os dez artigos mais citados pela área de Administração. Como esta área sozinha é responsável por 65\% de todas as citações ao Marketing, os artigos mais citados por esta área também são os mais citados na contagem geral. É bastante notável o dado que sete desses dez artigos sejam focados em metodologia, mais especificamente, em cuidados de modelagem e estatística. Os demais são focados em Marketing de Relacionamento e um em Marketing Estratégico. Tais dados sugerem uma supervalorização dada pela Administração à produção metodológica de Marketing em detrimento à teoria e aos temas particulares da área. Essa ênfase em metodologia parece ser congruente com a realizada pela própria área de Marketing (Brown et al., 2005), especificamente no que diz respeito à modelagem (Davis, Golicic, Boerstler, Choi, \& Oh, 2013). Além disso, cabe notar que estes dez artigos respondem aproximadamente por $13 \%$ de todas as citações recebidas pelo Marketing na Administração, assim como por quase $10 \%$ de todas as citações recebidas no conjunto total das áreas.

Tabela 2

Artigos de Marketing mais Citados por Top Journals de Administração, em 2006-2011

\begin{tabular}{lccccc}
\hline Título do artigo & Autores & Ano & Periódico & \multicolumn{2}{c}{ Citações } \\
\cline { 4 - 6 } & & & N & $\%$ \\
\hline Evaluating Structural Equation Models with & Fornell e Larcker & 1981 & JMR & 46 & 3,2 \\
Unobservable Variables and Measurement Error & Armstrong e & 1977 & JMR & 31 & 2,2 \\
Estimating Nonresponse Bias in Mail Surveys & Overton & & & & \\
A Critical Review of Construct Indicators & Jarvis, Mackenzie & 2003 & JCR & 25 & 1,7 \\
& e Podsakoff & & & & \\
Index Construction with Formative Indicators & Diamantopoulos & 2001 & JMR & 19 & 1,3 \\
& e Winklhofer & & & & \\
Do Norms Matter in Marketing Relationships? & Heide e John & 1992 & JM & 14 & 1,0 \\
Two Structural Equation Models: LISREL and PLS & Fornell e & 1982 & JMR & 13 & 0,9 \\
& Bookstein & & & & \\
A Paradigm for Developing Better Measures of Marketing & Churchill & 1979 & JMR & 12 & 0,8 \\
Constructs & & & & & \\
The Capabilities of Market-Driven Organizations & Day & 1994 & JM & 10 & 0,7 \\
Identification and Analysis of Moderator Variables & Sharma, Durand & 1981 & JMR & 10 & 0,7 \\
e Gur-Arie & & & & \\
The Commitment-Trust Theory of Relationship Marketing & Morgan e Hunt & 1994 & JM & 9 & 0,6 \\
\hline Total de citações recebidas por artigos de Marketing nos top journals de Administração & & 1441 & 100 \\
\hline
\end{tabular}

Os dez artigos mais citados pela área de Comunicação aparecem na Tabela 3. Nessa listagem, apenas o artigo de Fornell e Larcker (1981) é focado em considerações metodológicas, enquanto seis são contribuições relacionadas à Propaganda, dois são produções de Marketing Eletrônico e um é da área de Comportamento do Consumidor. 
Tabela 3

Artigos de Marketing mais Citados por Top Journals de Comunicação, em 2006-2011

\begin{tabular}{|c|c|c|c|c|c|}
\hline \multirow[t]{2}{*}{ Título do artigo } & \multirow[t]{2}{*}{ Autores } & \multirow[t]{2}{*}{ Ano } & \multirow[t]{2}{*}{ Periódico } & \multicolumn{2}{|c|}{ Citações } \\
\hline & & & & $\mathrm{N}$ & $\%$ \\
\hline Using drama to persuade & $\begin{array}{l}\text { Deighton, Romer } \\
\text { e McQueen }\end{array}$ & 1989 & JCR & 6 & 1,2 \\
\hline The Influence of Message Framing and Issue Involvement & $\begin{array}{l}\text { Maheswaran e } \\
\text { Meyers-Levy }\end{array}$ & 1990 & JMR & 6 & 1,2 \\
\hline $\begin{array}{l}\text { Measuring the Customer Experience in Online } \\
\text { Environments: A Structural Modeling Approach }\end{array}$ & $\begin{array}{l}\text { Novak, Hoffman } \\
\text { e Yung }\end{array}$ & 2000 & MS & 5 & 1,0 \\
\hline $\begin{array}{l}\text { Interactive Home Shopping: Consumer, Retailer and } \\
\text { Manufacturer Incentives to Participate in Electronic } \\
\text { Marketplaces }\end{array}$ & Alba et al. & 1997 & $\mathrm{JM}$ & 5 & 1,0 \\
\hline $\begin{array}{l}\text { The Power of Feelings in Understanding Advertising } \\
\text { Effects }\end{array}$ & Edell e Burke & 1987 & JCR & 5 & 1,0 \\
\hline $\begin{array}{l}\text { Evaluating Structural Equation Models with } \\
\text { Unobservable Variables and Measurement Error }\end{array}$ & Fornell e Larcker & 1981 & JMR & 5 & 1,0 \\
\hline $\begin{array}{l}\text { When to Accentuate the Negative: The Effects of } \\
\text { Perceived Efficacy and Message Framing on Intentions to } \\
\text { Perform a Health-Related Behavior }\end{array}$ & Block e Keller & 1995 & JMR & 4 & 0,8 \\
\hline $\begin{array}{l}\text { Sympathy and Empathy: Emotional Responses to } \\
\text { Advertising Dramas }\end{array}$ & Escalas e Stern & 2003 & $\mathrm{JCR}$ & 4 & 0,8 \\
\hline $\begin{array}{l}\text { What to Convey in Antismoking Advertisements for } \\
\text { Adolescents: The Use of Protection Motivation Theory to } \\
\text { Identify Effective Message Themes }\end{array}$ & $\begin{array}{l}\text { Pechmann, Zhao, } \\
\text { Goldberg e } \\
\text { Reibling }\end{array}$ & 2003 & $\mathrm{JM}$ & 4 & 0,8 \\
\hline Measuring the Involvement Construct & Zaichkowsky & 1985 & JCR & 4 & 0,8 \\
\hline Total de citações recebidas por artigos de Marketing nc & ournals de $\mathrm{Con}$ & ação & & 503 & 100 \\
\hline
\end{tabular}

Os artigos mais citados pelas demais áreas são listados na Tabela 4. Como o número de citações dos artigos de Marketing nessas áreas é bem menor, apenas os três mais citados em cada área são relacionados. Em Psicologia, os artigos mais referenciados são da área de Comportamento do Consumidor, com foco nas preferências e no processo decisório dos consumidores. Em Economia e Finanças, dois dos artigos mais citados também são relacionados às escolhas e às preferências dos consumidores, enquanto um trata do comportamento dos consumidores em relação a preços. Em Sociologia e Antropologia, por fim, um dos artigos mais citados é focado em metodologia experimental, enquanto os demais também pertencem à área de Comportamento do Consumidor. 
Tabela 4

Artigos de Marketing mais Citados por Top Journals em Cada Área em 2006-2011

\begin{tabular}{|c|c|c|c|c|c|}
\hline \multirow[t]{2}{*}{ Título do artigo } & \multirow[t]{2}{*}{ Autores } & \multirow[t]{2}{*}{ Ano } & \multirow[t]{2}{*}{ Periódico } & \multicolumn{2}{|c|}{ Citações } \\
\hline & & & & $\mathrm{N}$ & $\%$ \\
\hline \multicolumn{6}{|l|}{ Psicologia } \\
\hline $\begin{array}{l}\text { Discounting Time and Time Discounting: Subjective Time } \\
\text { Perception and Intertemporal Preferences }\end{array}$ & $\begin{array}{l}\text { Zauberman, Kim, } \\
\text { Malkoc e } \\
\text { Bettman }\end{array}$ & 2009 & JMR & 5 & 3,2 \\
\hline $\begin{array}{l}\text { Metacognitive Experiences in Consumer Judgment and } \\
\text { Decision Making }\end{array}$ & Schwarz & 2004 & $\mathrm{JCP}$ & 4 & 2,5 \\
\hline Preference fluency in Choice & $\begin{array}{l}\text { Novemsky, Dhar, } \\
\text { Schwarz e } \\
\text { Simonson }\end{array}$ & 2007 & JMR & 3 & 1,9 \\
\hline Total de citações recebidas nos top journals de Psicologia & & & & 162 & 100 \\
\hline \multicolumn{6}{|l|}{ Economia e Finanças } \\
\hline Mental Accounting and Consumer Choice & Thaler & 1985 & MS & 3 & 4,5 \\
\hline $\begin{array}{l}\text { Adding Asymmetrically Dominated Alternatives: Violating } \\
\text { of Regularity and the Similarity Hypothesis }\end{array}$ & $\begin{array}{l}\text { Huber, Payne e } \\
\text { Puto }\end{array}$ & 1982 & JCR & 2 & 3,0 \\
\hline $\begin{array}{l}\text { Divide and Prosper: Consumers' Reactions to Partitioned } \\
\text { Prices }\end{array}$ & $\begin{array}{l}\text { Morwitz, } \\
\text { Greenleaf e } \\
\text { Johnson }\end{array}$ & 1998 & JMR & 2 & 3,0 \\
\hline Total de citações recebidas nos top journals de Economia e & inanças & & & 66 & 100 \\
\hline \multicolumn{6}{|l|}{ Sociologia e Antropologia } \\
\hline Influentials, Networks and Public Opinion Formation & Watts e Dodds & 2007 & JCR & 3 & 7,1 \\
\hline $\begin{array}{l}\text { Efficient Experimental Design with Marketing Research } \\
\text { Applications }\end{array}$ & $\begin{array}{l}\text { Kuhfeld, Tobias e } \\
\text { Garratt }\end{array}$ & 1994 & JMR & 2 & 4,8 \\
\hline Determinants of Household Expenditures for Services & $\begin{array}{l}\text { Soberon-Ferrer e } \\
\text { Dardis }\end{array}$ & 1991 & JCR & 2 & 4,8 \\
\hline Total de citações recebidas nos top jo & & & & 42 & 100 \\
\hline
\end{tabular}

Conforme os dados apresentados, pelo menos no nível de análise de artigos individuais, os trabalhos mais referenciados têm sido os de método, especialmente na Administração. Nas demais áreas, produções de temas específicos da área já ganham mais importância, especialmente os de Comportamento de Consumidor, embora, individualmente, nenhum artigo desse tema ganhe um número muito elevado de citações.

\section{Indicadores da contribuição de temas de Marketing}

Como mencionado na seção de Método deste trabalho, o processo de clusterização em temas se deu em função das diferentes tendências de citação por outras áreas, isto é, pela forma como eles são percebidos como diferentes pelas demais ciências sociais. Assim, por exemplo, satisfação do consumidor, decisão e escolha do consumidor e psicologia do consumidor constituem temas distintos porque as respectivas produções não contribuem da mesma forma para as mesmas áreas, ainda que todos possam ser estudados dentro da disciplina de Comportamento do Consumidor. Da mesma maneira, embora precificação e varejo não sejam necessariamente assuntos semelhantes para o Marketing, as produções ligadas a esses assuntos tendem a ser vistas como próximas pelas demais áreas e a serem citadas conjuntamente. O grupo outros tópicos corresponde a uma grande diversidade de assuntos 
específicos, sendo que nenhum deles tem contribuição suficiente para ser considerado um tema próprio de Marketing. A Tabela 5 apresenta os temas encontrados e a frequência de ocorrência de cada um nas citações de cada área. Os nomes dados aos temas correspondem aos termos mais representativos das palavras-chave em cada agrupamento.

Tabela 5

Ocorrência dos Temas de Marketing em Citações pelas Ciências Sociais

\begin{tabular}{lcccccc}
\hline Cluster & Adm & Com & Psi & Eco \& Fin & Soc \& Ant & Total \\
\hline Negócios, mercados e relacionamento & 23323 & 1165 & 211 & 364 & 181 & 25244 \\
Comportamento e psicologia do consumidor & 16993 & 5158 & 2032 & 644 & 319 & 25146 \\
Estratégia e Marketing industrial & 15447 & 1082 & 269 & 231 & 203 & 17232 \\
Performance e qualidade & 14337 & 1123 & 312 & 122 & 176 & 16070 \\
Método e pesquisa em Marketing & 10566 & 1464 & 266 & 204 & 293 & 12793 \\
Estatística & 8910 & 884 & 96 & 41 & 255 & 10186 \\
Produto & 5716 & 922 & 261 & 334 & 59 & 7292 \\
Precificação e varejo & 5217 & 603 & 152 & 476 & 66 & 6514 \\
Decisão e escolha do consumidor & 3646 & 1236 & 682 & 335 & 59 & 5958 \\
E-commerce e internet & 3641 & 1312 & 233 & 64 & 50 & 5300 \\
Branding & 3562 & 873 & 205 & 280 & 9 & 4929 \\
Propaganda & 2288 & 1570 & 107 & 68 & 19 & 4052 \\
Modelos & 3474 & 311 & 84 & 107 & 43 & 4019 \\
Satisfação do consumidor & 2351 & 483 & 146 & 14 & 14 & 3008 \\
Outros tópicos & 5822 & 2380 & 500 & 250 & 153 & 9105 \\
\hline Total & 125293 & 20566 & 5556 & 3534 & 1899 & 156848 \\
\hline
\end{tabular}

Dois insights podem ser extraídos imediatamente desta tabela. Em primeiro lugar, embora os artigos de Marketing mais citados individualmente por outras áreas tratem sobre metodologia, modelagem e estatística, no conjunto total das contribuições, outros temas são os mais preponderantes nas citações. No total, dois temas gerais se destacam: o primeiro é ligado aos negócios, às discussões de mercado e ao Marketing de Relacionamento; o segundo trata do comportamento dos consumidores, envolvendo aspectos psicológicos dos mesmos. Depois desses temas, considerações estratégicas e de indústria no Marketing, performance das empresas e qualidade são também bastante presentes nas citações. Na sequência, vêm os temas de método em Marketing e estatística, além de outros.

Em segundo lugar, percebe-se que a frequência dos temas nas citações de cada área é bastante diferente. $\mathrm{O}$ tema de negócios, mercados e relacionamentos em Marketing tem quase todas as suas citações provenientes da Administração e contribui relativamente pouco para as demais áreas. Por outro lado, o tema de método e pesquisa em Marketing possui uma contribuição aparentemente mais proporcional ao volume total de citações em cada área. De fato, como demonstra a análise de tabulação cruzada da Tabela 6 , os diferentes temas encontram-se associados de forma distinta às ciências sociais. 
Tabela 6

Análise de Tabulação Cruzada entre os Temas de Marketing e as Ciências Sociais

\begin{tabular}{lccccc}
\hline \multirow{2}{*}{ Cluster } & \multicolumn{5}{l}{ Resíduos padronizados ajustados } \\
\cline { 2 - 6 } & Adm & Com & Psi & Eco \& Fin & Soc \& Ant \\
\hline Negócios, mercados e relacionamento & $54,1^{\mathrm{c}}$ & $-43,7^{\mathrm{a}}$ & $-25,4^{\mathrm{d}}$ & $-9,5^{\mathrm{b}}$ & $-7,8^{\mathrm{b}}$ \\
Comportamento e psicologia do consumidor & $-53,1^{\mathrm{c}}$ & $37,9^{\mathrm{a}}$ & $42,5^{\mathrm{d}}$ & $3,6^{\mathrm{b}}$ & $0,9^{\mathrm{b}}$ \\
Estratégia e Marketing industrial & $33,9^{\mathrm{c}}$ & $-28,2^{\mathrm{a}}$ & $-14,9^{\mathrm{a}}$ & $-8,6^{\mathrm{b}}$ & $-0,4^{\mathrm{d}}$ \\
Performance e qualidade & $31,2^{\mathrm{c}}$ & $-24,3^{\mathrm{a}}$ & $-11,6^{\mathrm{a}}$ & $-13,5^{\mathrm{b}}$ & $-1,4^{\mathrm{d}}$ \\
Método e pesquisa em Marketing & $8^{\mathrm{c}}$ & $-5,8^{\mathrm{a}}$ & $-9,3^{\mathrm{d}}$ & $-5,2^{\mathrm{b}}$ & $11,7^{\mathrm{e}}$ \\
Estatística & $19,8^{\mathrm{c}}$ & $-13,7^{\mathrm{a}}$ & $-14,7^{\mathrm{d}}$ & $-13^{\mathrm{b}}$ & $12,3^{\mathrm{e}}$ \\
Produto & $-3,3^{\mathrm{a}}$ & $-1,2^{\mathrm{a}}$ & $0,2^{\mathrm{a}}$ & $13,7^{\mathrm{b}}$ & $-3,2^{\mathrm{c}}$ \\
Precificação e varejo & $0,4^{\mathrm{c}}$ & $-9,4^{\mathrm{a}}$ & $-5,4^{\mathrm{a}}$ & $28,1^{\mathrm{b}}$ & $-1,5^{\mathrm{a}, \mathrm{c}}$ \\
Decisão e escolha do consumidor & $-36,7^{\mathrm{c}}$ & $17,8^{\mathrm{a}}$ & $33,7^{\mathrm{d}}$ & $17,9^{\mathrm{b}}$ & $-1,6^{\mathrm{c}}$ \\
E-commerce e internet & $-20,7^{\mathrm{c}}$ & $25,5^{\mathrm{a}}$ & $3,4^{\mathrm{d}}$ & $-5,2^{\mathrm{b}}$ & $-1,8^{\mathrm{c}}$ \\
Branding & $-13,6^{\mathrm{c}}$ & $9,7^{\mathrm{a}}$ & $2,4^{\mathrm{a}}$ & $16,5^{\mathrm{b}}$ & $-6,7^{\mathrm{d}}$ \\
Propaganda & $-37,7^{\mathrm{b}}$ & $49^{\mathrm{a}}$ & $-3,1^{\mathrm{b}}$ & $-2,5^{\mathrm{b}}$ & $-4,4^{\mathrm{c}}$ \\
Modelos & $10,5^{\mathrm{b}}$ & $-10,2^{\mathrm{a}}$ & $-5^{\mathrm{a}}$ & $1,8^{\mathrm{b}}$ & $-0,8^{\mathrm{b}}$ \\
Satisfação do consumidor & $-2,4^{\mathrm{c}}$ & $4,8^{\mathrm{a}}$ & $3,9^{\mathrm{a}}$ & $-6,7^{\mathrm{b}}$ & $-3,8^{\mathrm{b}}$ \\
Outros tópicos & $-39,1^{\mathrm{c}}$ & $37,9^{\mathrm{a}}$ & $10,4^{\mathrm{d}}$ & $3,3^{\mathrm{b}}$ & $4,2^{\mathrm{b}, \mathrm{d}}$ \\
\hline
\end{tabular}

Nota. O valor do teste de Qui-quadrado de Pearson é 16661,343 ( $\mathrm{df}=56$ ).

a, b, c, d, e Cada letra em sobrescrito representa um grupo em que as proporções não diferem entre si a 5\% de significância.

Naturalmente, vários temas de Marketing que interessam mais a certas áreas estão entre os que têm uma intersecção com os interesses de pesquisa destas. Por exemplo, propaganda, e-commerce e internet contribuem bem mais para os estudos de Comunicação do que para os das demais áreas. Precificação e varejo contribuem proporcionalmente mais para a Economia e Finanças. Comportamento e psicologia do consumidor são considerados temas mais importantes pela Psicologia, embora ele também seja importante para outras áreas, como a Comunicação. Os temas de estratégia, performance, qualidade, negócios, mercados e relacionamentos em Marketing são muito mais referenciados pela Administração.

Anteriormente, Pieters e Baumgertner (2002) já haviam buscado relacionar a contribuição de subáreas da Administração, incluindo Marketing, entre si e em relação a algumas outras áreas. Entretanto, essa contribuição havia sido estudada apenas tomando o Marketing como um todo, e não escrutinizando os diversos tópicos da disciplina e como a importância de cada um pode ser substancialmente diferente. Nesse sentido, ao se observar o conjunto das intensidades e valências dos resíduos na Tabela 6 , percebe-se que há uma tendência de polarização das contribuições de vários temas entre a Administração e as demais áreas, no sentido de que, quanto mais um tema está associado com a Administração, menos ele está com as demais ciências sociais (e vice-versa). Isto é, enquanto alguns temas de Marketing contribuem quase que exclusivamente para os interesses de pesquisa da Administração, outros contribuem para as demais ciências de uma forma geral, mas não são considerados tão importantes para a Administração.

A percepção desse fenômeno de polarização dos temas de Marketing é mais perceptível de forma visual, através do grafo de interconexões dos temas citados apresentado na Figura 1. A fim de enxergar o comportamento geral de cada área como um todo, as unidades de representação nesse grafo foram as 78 categorias formadas pela combinação de palavras-chaves semelhantes, e não os quinze temas finais

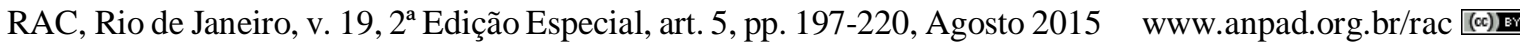


resultantes após a clusterização, a fim de permitir que a multiplicidade de vértices formasse nuvens de áreas no grafo. $\mathrm{O}$ algoritmo utilizado nos layouts foi o Harel-Koren Fast Multiscale, apropriado para grafos com um grande número de vértices.

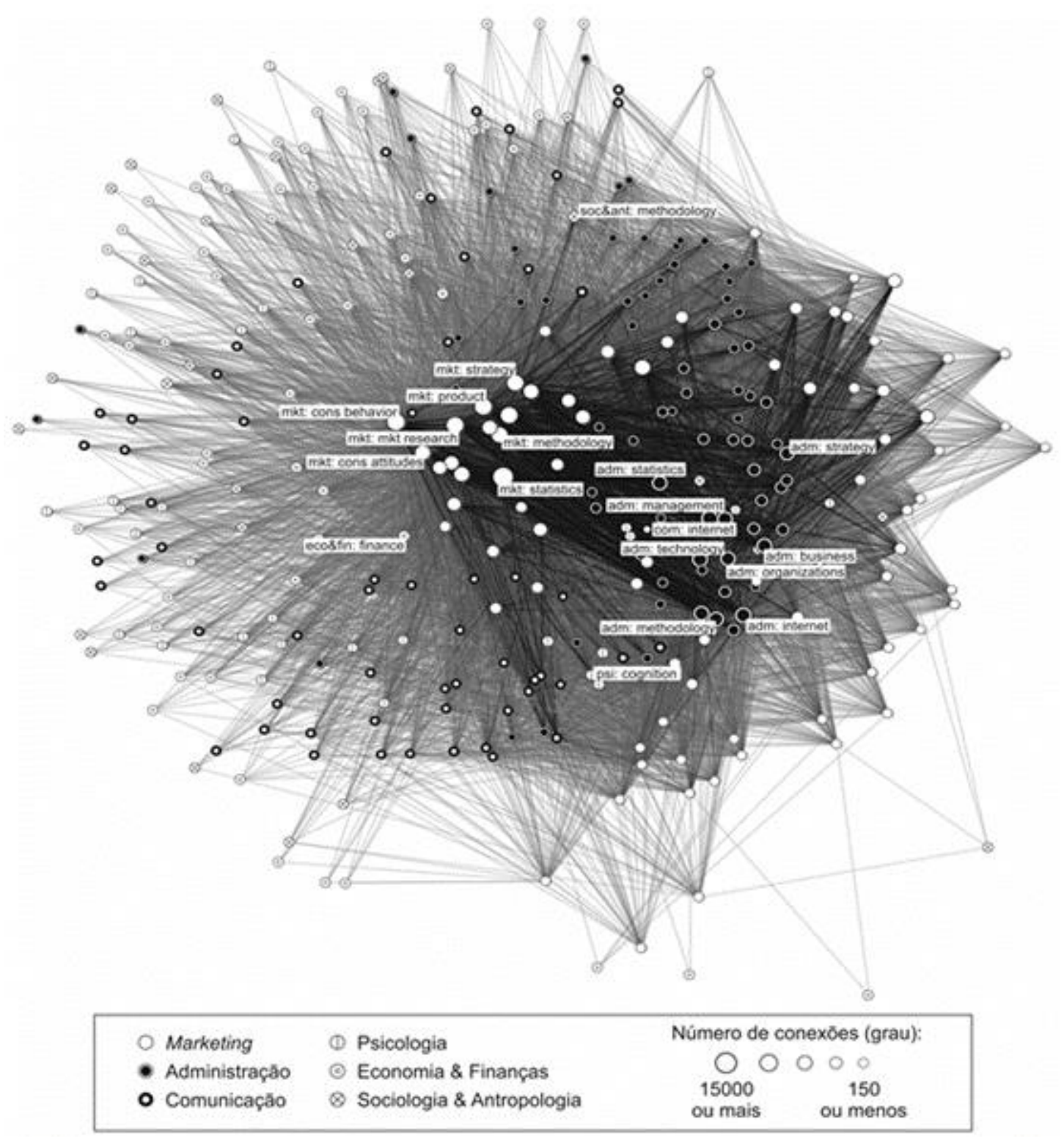

Figura 1. Citações das Categorias de Marketing pelas Categorias das Demais Ciências Sociais

Cada vértice no grafo é uma categoria representando grupos de palavras-chave semelhantes nos artigos. Apenas as categorias com maior número de conexões são nomeadas na Figura, além da principal de cada área. Todas as conexões são direcionais, no sentido de uma categoria de uma ciência social para uma categoria de Marketing.

Percebe-se, que os vértices de Marketing encontram-se no meio e na direita do grafo, separados em dois grupos pelo conjunto dos vértices da Administração. Os vértices da Comunicação, da Psicologia, de Economia e Finanças, e de Sociologia e Antropologia encontram-se difusos e espalhados no hemisfério esquerdo do grafo. Essa disposição de vértices pode ser interpretada da seguinte maneira: os vértices (categorias) conectados a um maior número de outros vértices são os que possuem mais centralidade e estão no meio do grafo. Logo, as categorias de Marketing nesta região são as que contribuem de forma mais geral para o conjunto das disciplinas. Da mesma forma, os vértices de outras áreas próximos ao centro do grafo são os que citam uma diversidade maior de assuntos de Marketing. 
Por outro lado, as categorias de Marketing com menos conexões são afastadas para a periferia do grafo, ficando próximas das categorias das outras áreas que as citam. Essas são as categorias de Marketing localizadas à direita, que ficam separadas das demais pelos vértices da Administração, indicando que elas basicamente contribuem apenas para essa área. Além disso, o fato de os vértices da Administração ficarem mais juntos uns dos outros e se posicionarem no hemisfério oposto aos das demais áreas indica que as conexões (citações) que elas fazem ao Marketing tendem a ser em direção a vértices diferentes e a ter uma natureza distinta. Enquanto isso, os vértices das outras ciências encontram-se espalhados e misturados uns com os outros porque recebem contribuições relativamente semelhantes do Marketing, mas diferentes da Administração.

Assim, se a pergunta qual a contribuição do Marketing para as demais áreas fosse respondida apenas pelo grafo da Figura 1, a resposta seria de que os tópicos mais centrais, isto é, os ligados à metodologia, ao comportamento do consumidor e, em menor grau, à estratégia são os que mais contribuem para as ciências como um todo, enquanto aqueles à direita (relacionados ao composto de Marketing, relacionamento, vendas, ética e outros tópicos) contribuem basicamente apenas para a Administração.

A contribuição particular de cada tema de Marketing para as demais áreas pode ser mais bem examinada através do grafo da Figura 2, em que as categorias de Marketing encontram-se unidas nos quinze temas da Tabela 5 e em que os vértices das outras áreas são concentrados em apenas um ponto. O algoritmo utilizado no layout deste grafo é o Fruchterman-Reingold, em que o número de conexões representado por cada linha (representado pela espessura das linhas) influencia na força de atração e aproxima vértices com mais ligações entre si.

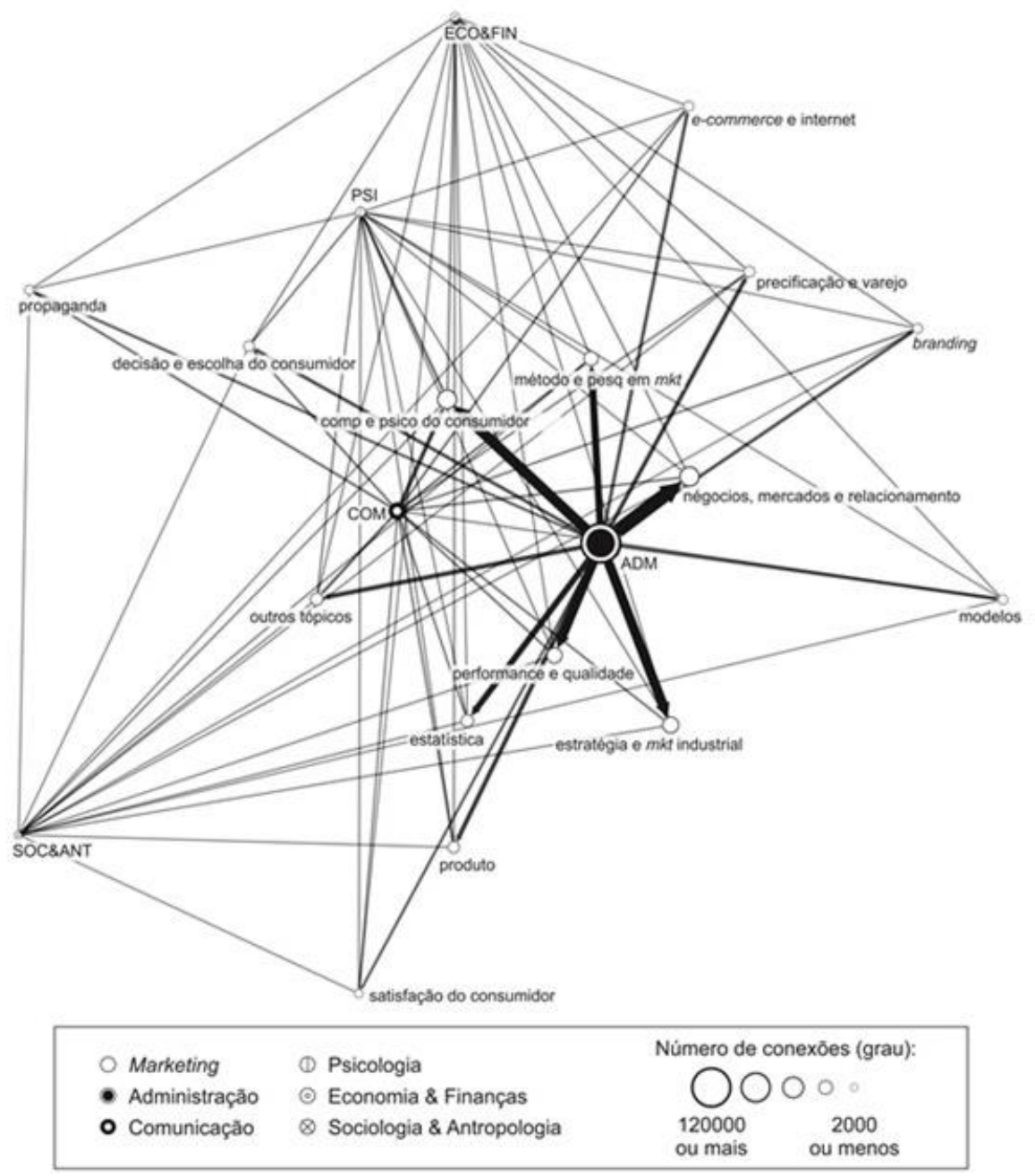

Figura 2. Citações dos Temas de Marketing nas Ciências Sociais 
A posição central de Administração e Comunicação no grafo indica que essas áreas referenciam uma maior variedade de temas de Marketing, assim como a posição central do tema comportamento e psicologia do consumidor indica que esse tema é o que contribui de forma mais universal para as demais ciências, seguido por método e pesquisa em Marketing. A Administração é a ciência que mais cita a produção de Marketing, focando nesses temas, mas também em estatística, estratégia, Marketing industrial, performance, qualidade e, principalmente, mercados e Marketing de relacionamento. Como a maioria desses temas é de interesse quase exclusivo da Administração, eles encontram-se mais para a periferia do grafo, afastados das outras ciências.

Encontram-se distantes também as áreas de Economia e Finanças, além de Sociologia e Antropologia, em função da contribuição baixa do Marketing para elas. As duas áreas referenciam principalmente trabalhos de comportamentos do consumidor, porém a Economia e as Finanças se interessam relativamente bastante também por precificação e varejo, decisão e escolha do consumidor, produto e branding, enquanto a Sociologia e a Antropologia também tem um interesse considerável pela produção de método e pesquisa em Marketing. A Psicologia, embora referencie vários temas de Marketing, tem se concentrado fortemente na produção de comportamento e psicologia do consumidor, incluindo aspectos do processo decisório. A Comunicação tem um interesse também forte em comportamento do consumidor, mas também em método, propaganda, e-commerce e internet. Cabe destacar que esse interesse da Comunicação pela produção de Marketing não havia sido explorado na análise das citações de diversas áreas de Pieters e Baumgartner (2002), embora tenha sido revelado aqui como o mais importante entre os de todas as áreas depois da Administração (ver também Tabela 1).

\section{Indicadores da contribuição de periódicos de Marketing}

O terceiro nível de análise da contribuição de Marketing para as demais áreas, toma como unidade de análise os seus principais periódicos e é apresentada na Tabela 7. Interessantemente, o Journal of Marketing, periódico de maior fator de impacto, não é o que contribui mais para as demais ciências, mas sim o Journal of Marketing Research. O número de citações do Journal of Marketing é quase igualado pelo Journal of Consumer Research, que é focado apenas em Comportamento do Consumidor e não em todos os temas de Marketing. O periódico com o segundo maior fator de impacto da área, o Journal of Retailing, tem tanta contribuição para as demais áreas quanto periódicos de fator de impacto bem menor.

Tabela 7

Citações de Periódicos de Marketing nos Top Journals das Ciências Sociais em 2006-2011

\begin{tabular}{|c|c|c|c|c|c|c|c|c|c|c|c|c|}
\hline \multirow[t]{2}{*}{ Periódico } & \multicolumn{6}{|c|}{ Artigos citados } & \multicolumn{6}{|c|}{ Citações recebidas } \\
\hline & Adm & Com & Psi & $\begin{array}{l}\text { Eco } \\
\& \text { Fin }\end{array}$ & $\begin{array}{l}\text { Soc } \\
\& \text { Ant }\end{array}$ & Total & Adm & Com & Psi & $\begin{array}{l}\text { Eco } \\
\& \text { Fin }\end{array}$ & $\begin{array}{l}\text { Soc } \\
\& \text { Ant }\end{array}$ & Total \\
\hline $\begin{array}{l}\text { Journal of Marketing } \\
\text { Research }\end{array}$ & 209 & 69 & 28 & 18 & 15 & 296 & 450 & 97 & 36 & 19 & 16 & 618 \\
\hline Journal of Marketing & 268 & 79 & 5 & 3 & 3 & 329 & 473 & 113 & 5 & 3 & 3 & 597 \\
\hline $\begin{array}{l}\text { Journal of Consumer } \\
\text { Research }\end{array}$ & 155 & 143 & 87 & 21 & 12 & 354 & 229 & 190 & 94 & 22 & 16 & 551 \\
\hline Marketing Science & 94 & 14 & 3 & 15 & 1 & 117 & 126 & 19 & 3 & 17 & 1 & 166 \\
\hline $\begin{array}{l}\text { Journal of Consumer } \\
\text { Psychology }\end{array}$ & 29 & 19 & 15 & 2 & 1 & 60 & 35 & 24 & 20 & 2 & 1 & 82 \\
\hline Journal of Retailing & 40 & 10 & 0 & 1 & 0 & 47 & 50 & 14 & 0 & 1 & 0 & 65 \\
\hline
\end{tabular}


Tabela 7 (continuação)

\begin{tabular}{|c|c|c|c|c|c|c|c|c|c|c|c|c|}
\hline \multirow[t]{2}{*}{ Periódico } & \multicolumn{6}{|c|}{ Artigos citados } & \multicolumn{6}{|c|}{ Citações recebidas } \\
\hline & Adm & Com & Psi & $\begin{array}{l}\text { Eco } \\
\& \text { Fin }\end{array}$ & $\begin{array}{l}\text { Soc } \\
\& \text { Ant }\end{array}$ & Total & Adm & Com & Psi & $\begin{array}{l}\text { Eco } \\
\& \text { Fin }\end{array}$ & $\begin{array}{l}\text { Soc } \\
\& \text { Ant }\end{array}$ & Total \\
\hline $\begin{array}{l}\text { Journal of Interactive } \\
\text { Marketing }\end{array}$ & 23 & 15 & 2 & 0 & 1 & 33 & 24 & 17 & 2 & 0 & 1 & 44 \\
\hline $\begin{array}{l}\text { Journal of Public Policy \& } \\
\text { Marketing }\end{array}$ & 18 & 11 & 2 & 1 & 0 & 32 & 24 & 12 & 2 & 1 & 0 & 39 \\
\hline Journal of Consumer Affairs & 6 & 13 & 0 & 1 & 3 & 23 & 6 & 14 & 0 & 1 & 4 & 25 \\
\hline Journal of Service Research & 14 & 3 & 0 & 0 & 0 & 16 & 17 & 3 & 0 & 0 & 0 & 20 \\
\hline $\begin{array}{l}\text { Journal of International } \\
\text { Marketing }\end{array}$ & 7 & 0 & 0 & 0 & 0 & 7 & 7 & 0 & 0 & 0 & 0 & 7 \\
\hline Total & 863 & 376 & 142 & 62 & 36 & 1314 & 1441 & 503 & 162 & 66 & 11 & 2214 \\
\hline
\end{tabular}

Segundo Stremersch, Verniers e Verhoef (2007), os artigos de Marketing que mais recebem citações são os do Journal of Marketing (o que se reflete naturalmente no seu fator de impacto mais alto), porém, contrastando-se esse dado com os resultados deste trabalho, assim como com as percepções apontadas por Cote et al. (1992), conclui-se que boa parte da valorização desse periódico é endógena. Existe, assim, uma grande diferença entre o impacto que a produção de um periódico de Marketing representa dentro da própria área e fora dela.

A importância de cada periódico para as demais áreas pode ser examinada na Tabela 8. Quase $80 \%$ das citações recebidas por Marketing são para o Journal of Marketing Research, o Journal of Marketing e o Journal of Consumer Research, sendo a contribuição dos dois primeiros mais focada na Administração e, a do terceiro, mais focada nas demais ciências.

Tabela 8

Análise de Tabulação Cruzada entre Periódicos de Marketing e Ciências Sociais

\begin{tabular}{lccccc}
\hline \multirow{2}{*}{ Periódico } & \multicolumn{6}{c}{ Resíduos padronizados ajustados } \\
\cline { 2 - 6 } & Adm & Com & Psi & Eco \& Fin & Soc \& Ant \\
\hline Journal of Marketing Research & $4,7^{\mathrm{c}}$ & $-4,9^{\mathrm{a}}$ & $-1,7^{\mathrm{a}}$ & $0,2^{\mathrm{a}, \mathrm{b}, \mathrm{c}}$ & $1,5^{\mathrm{b}, \mathrm{c}}$ \\
Journal of Marketing & $8,5^{\mathrm{c}}$ & $-2,6^{\mathrm{a}}$ & $-7,1^{\mathrm{b}}$ & $-4,2^{\mathrm{b}}$ & $-2,9^{\mathrm{b}}$ \\
Journal of Consumer Research & $-13,4^{\mathrm{b}}$ & $7,6^{\mathrm{a}}$ & $10,1^{\mathrm{c}}$ & $1,6^{\mathrm{a}}$ & $2,0^{\mathrm{a}}$ \\
Marketing Science & $3,0^{\mathrm{c}}$ & $-3,6^{\mathrm{a}}$ & $-2,8^{\mathrm{a}}$ & $5,7^{\mathrm{b}}$ & $-1,3^{\mathrm{a}, \mathrm{c}}$ \\
Journal of Consumer Psychology & $-4,3^{\mathrm{b}}$ & $1,4^{\mathrm{a}}$ & $6,0^{\mathrm{c}}$ & $-0,3^{\mathrm{a}, \mathrm{b}}$ & $-0,5^{\mathrm{a}, \mathrm{b}, \mathrm{c}}$ \\
Journal of Retailing & $2,0^{\mathrm{a}}$ & $-0,2^{\mathrm{a}}$ & $-2,3^{\mathrm{b}}$ & $-0,7^{\mathrm{a}, \mathrm{b}}$ & $-1,1^{\mathrm{a}, \mathrm{b}}$ \\
Journal of Interactive Marketing & $-1,5^{\mathrm{b}}$ & $2,5^{\mathrm{a}}$ & $-0,7^{\mathrm{a}, \mathrm{b}}$ & $-1,2^{\mathrm{a}, \mathrm{b}}$ & $0,2^{\mathrm{a}, \mathrm{b}}$ \\
Journal of Public Policy \& Marketing & $-0,5^{\mathrm{a}}$ & $1,2^{\mathrm{a}}$ & $-0,5^{\mathrm{a}}$ & $-0,2^{\mathrm{a}}$ & $-0,9^{\mathrm{a}}$ \\
Journal of Consumer Affairs & $-4,3^{\mathrm{c}}$ & $4,0^{\mathrm{a}}$ & $-1,4^{\mathrm{c}}$ & $0,3^{\mathrm{a}, \mathrm{b}, \mathrm{c}}$ & $5,2^{\mathrm{b}}$ \\
Journal of Service Research & $1,9^{\mathrm{a}}$ & $-0,8^{\mathrm{a}}$ & $-1,3^{\mathrm{a}}$ & $-0,8^{\mathrm{a}}$ & $-0,6^{\mathrm{a}}$ \\
Journal of International Marketing & $1,9^{\mathrm{a}}$ & $-1,4^{\mathrm{a}}$ & $-0,7^{\mathrm{a}}$ & $-0,5^{\mathrm{a}}$ & $-0,4^{\mathrm{a}}$ \\
\hline
\end{tabular}

Nota. O valor do teste de Qui-quadrado de Pearson é de 417,162 (df =40).

a, b, c Cada letra em sobrescrito representa um grupo em que as proporções não diferem entre si a 5\% de significância. 
O Marketing Science possui uma quantidade considerável de citações, especialmente na Administração e em Economia e Finanças. A produção dos demais periódicos é relativamente pouco citada. Alguns periódicos - Journal of Retailing, Journal of Service Research e Journal of International Marketing - contribuem quase exclusivamente para a Administração.

Por fim, a Figura 3 apresenta as conexões entre os periódicos de cada área. No centro do grafo, encontram-se os quatro periódicos de Marketing mais citados, cercados pelos periódicos de outras áreas que mais fazem citações. Percebe-se que boa parte da contribuição de Marketing para as ciências sociais é concentrada em poucos periódicos. Apenas dois deles, o MIS Quarterly e o Strategic Management Journal respondem por $51 \%$ de todas as citações de Marketing na base de dados $(611$ e 519, respectivamente). Enquanto o primeiro tem maior associação com o Journal of Consumer Research, o segundo referencia mais o Journal of Marketing Research e o Journal of Marketing.

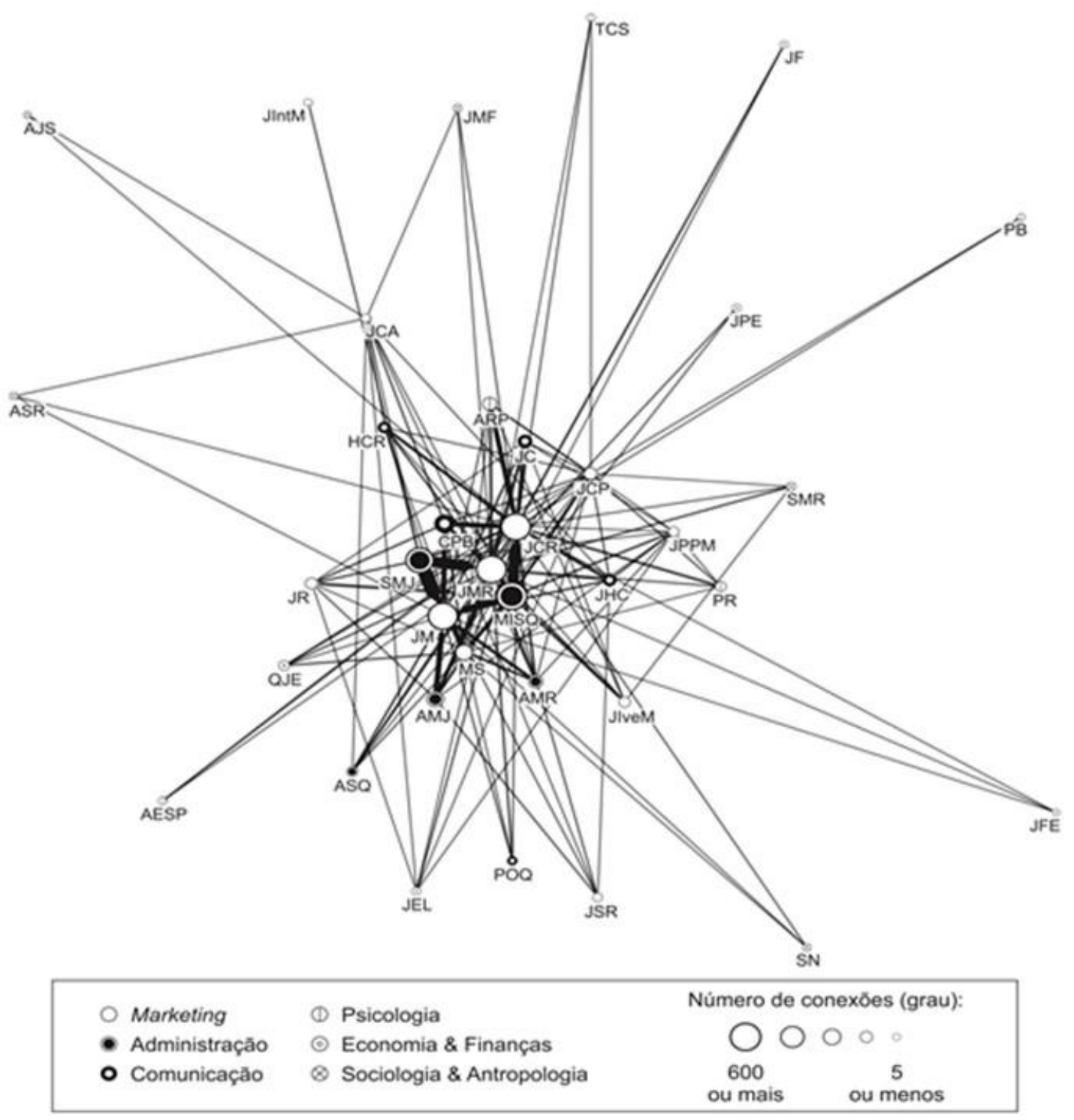

Figura 3. Citações dos Periódicos de Marketing nos Periódicos das Ciências Sociais

Nota. Advances in Experimental Social Psychology (AESP); American Journal of Sociology (AJS); Academy of Management Journal (AMJ); Academy of Management Review (AMR); Annual Review of Psychology (ARP); Administrative Science Quarterly (ASQ); American Sociological Review (ASR); Cyberpsychology, Behavior and Social Networking (CPB); Human Communication Research (HCR); Journal of Communication (JC); Journal of Consumer Affairs (JCA); Journal of Consumer Psychology (JCP); Journal of Consumer Research (JCR); Journal of Economic Literature (JEL); Journal of Finance (JF); Journal of Financial Economics (JFE); Journal of Health Communication (JHC); Journal of International Marketing (JIntM); Journal of Interactive Marketing (JIveM); Journal of Marketing (JM); Journal of Marketing Research (JMR); Journal of Marriage and Family (JMF); Journal of Political Economy (JPE); Journal of Public Policy \& Marketing (JPPM); Journal of 
Retailing (JR); Journal of Service Research (JSR); Marketing Science (MS); MIS Quarterly (MISQ); Psychological Bulletin (PB); Public Opinion Quarterly (POQ); Psychological Review (PR); Quarterly Journal of Economics (QJE); Social Networks (SN); Sociological Methods and Research (SMR); Strategic Management Journal (SMJ); Trends in Cognitive Sciences (TCS).

O Cyberpsychology, Behavior and Social Networking é um periódico da Comunicação que também tem se interessado bastante pela produção de Marketing (232 citações), seguido pelo Academy of Management Journal (161 citações) e pelo Academy of Management Review (109 citações) da Administração e pelo Annual Review of Psychology (104 citações) da Psicologia. Cabe notar que o periódico de Marketing citado de forma mais universal, isto é, aquele que recebe citações de uma maior variedade de fontes é o Journal of Consumer Research, que se encontra mais no centro geográfico do grafo, embora o Journal of Marketing e o Journal of Marketing Research tenham um número maior de citações em função da importância dada pela Administração (especialmente pelo Strategic Management Journal) nas citações desses periódicos. Esse dado, juntamente com as percepções das análises anteriores, sugere que o Comportamento do Consumidor vem sendo considerado um campo de interesse mais geral do que o conjunto dos demais temas de pesquisa do Marketing.

\section{Conclusões e Implicações do Estudo}

Os resultados desta análise bibliométrica permitem elaborar diversas conclusões. A primeira delas, e talvez a mais evidente, é a baixa contribuição do conjunto da produção de Marketing para a maioria das ciências sociais, exceto para a Administração, cujos estudos da área são mais citados. Os artigos de Marketing mais individualmente citados por essa área são relacionados a cuidados metodológicos, modelagem e estatística. Embora esse dado denote um reconhecimento positivo do rigor metodológico adotado na disciplina (Brown et al., 2005), ele também preocupa porque pode estar relacionado a uma simultânea desvalorização da produção teórica de Marketing. Cabe notar, porém, que esse resultado é referente às citações pela Administração e não pelas outras áreas, que citam muito pouco a produção sobre método em Marketing.

De forma geral, comparando as associações de temas com cada área, a produção de Marketing parece contribuir para as demais ciências em dois polos (Figura 1): um gerencial, voltado ao estudo de Marketing de Relacionamento, Marketing Estratégico, Marketing Industrial, performance e qualidade das empresas; e outro de consumo, abrangendo o comportamento do consumidores nos aspectos de preferências, escolhas e processo decisório especialmente. Embora o polo de Comportamento do Consumidor também contribua para a Administração, ele é proporcionalmente menos aproveitado por essa área do que pelos temas gerenciais, dado o volume de citações de cada tema. De outro lado, os temas do polo gerencial de Marketing estão entre os menos citados pelas demais ciências, incluindo até mesmo a área de Economia e Finanças, que também compartilham interesse pelo funcionamento dos mercados e pelas atividades das empresas.

A área de Comunicação referencia bastante temas que são interesses compartilhados de pesquisa com o Marketing, como propaganda, e-commerce e internet, além do Comportamento do Consumidor. Já o interesse da Psicologia é dominado amplamente pela produção de Comportamento de Consumidor, o que não surpreende, dada a grande contribuição que esse tema recebeu das Psicologias Comportamental e Experimental, em seus desenvolvimentos. Cabe destacar o dado positivo de que os trabalhos de Marketing citados na Psicologia são recentes (mais da metade possuem menos de cinco anos de idade). A atualidade com que os temas de Comportamento do Consumidor vêm sendo recebidos na Psicologia sugere que a sua produção recebe atenção e é considerada importante por essa área.

Por outro lado, o interesse da Economia, da Sociologia e da Antropologia no Marketing é ainda muito baixo, confirmando as percepções de Pieters e Baumgartner (2002). Entre o pequeno volume de citações feitas, os dados indicam preferência dessas áreas por artigos de Comportamento do Consumidor - além de precificação e varejo, no caso da Economia. 
O interesse mais geral das ciências sociais por Comportamento do Consumidor se reflete na verificação da centralidade do Journal of Consumer Research na rede de contribuições. O Journal of Marketing e o Journal of Marketing Research acumulam mais citações somente graças à valorização recebida pelo Strategic Management Journal. O Journal of Retailing, publicação de Marketing com segundo maior fator de impacto de cinco anos, contribui basicamente apenas para a Administração, acumulando menos citações que os periódicos citados e que o Marketing Science e o Journal of Consumer Psychology.

Sumarizando os resultados, o Comportamento do Consumidor vem despontando como o campo de maior status científico do Marketing fora da disciplina, responsável pela maioria do interesse externo da Economia e das ciências mais puras. À parte disto, o Marketing contribui de forma predominante para a Administração nos campos de interesse mais gerencial e metodológico - porém, pode-se questionar o quanto dessa contribuição é de cunho teórico do Marketing, isto é, vai além de resultados pontuais ou empíricos ou de desenvolvimentos em ferramentas metodológicas úteis para propósitos gerais dos pesquisadores. Pode-se questionar também a ausência de contribuição do Marketing Social ou do Macromarketing, isto é, do Marketing no escopo amplo como um processo social (Kotler \& Levy, 1969). De fato, os termos marketing social ou macromarketing ocorreram ocasionalmente nas citações, mas em quantidade tão pequena que foram agrupados na categoria outros tópicos.

Os resultados obtidos permitem, ainda, realizar alguns questionamentos em relação à contribuição científica de Marketing. Primeiramente, é possível que a polarização verificada nos interesses das demais áreas seja uma evidência da emergência do Comportamento do Consumidor como uma disciplina independente, isto é, focada em fenômenos de consumo à parte das possíveis implicações gerenciais para as práticas de Marketing nas empresas? Essa possibilidade é corroborada pelo baixo interesse da maioria das áreas (Economia, Psicologia, Sociologia e Antropologia) na produção dos temas mais gerenciais e estratégicos de Marketing, o que sugere que o aproveitamento de Comportamento do Consumidor por elas não se deve (pelo menos em grande parte) aos impactos gerenciais dos estudos neste tema.

Além disso, é possível que o predomínio crescente de trabalhos empíricos sobre teóricos (como argumentado por Yadav, 2010) esteja prejudicando o status científico de Marketing? Em paralelo a isso, é possível que a reputação da disciplina sofra também em função do pouco conhecimento de pesquisadores de outras áreas sobre os objetos de estudo do Marketing, assim como em função da imagem difundida de servir mais para o interesse das empresas do que para o bem-estar da sociedade (Silveira, Esteves, \& Rossi, 2013)? Pode-se notar nos resultados deste estudo que o interesse de outras áreas sobre o Marketing é maior em relação aos estudos focados nos consumidores e não nas empresas.

Por fim, há de se questionar se a evolução do Marketing a partir da incorporação do conhecimento de outras ciências para atender as necessidades das empresas tem condicionado a disciplina a ser muito mais uma ciência aplicada do que social - isto é, levado a disciplina a deixar de lado a produção de conhecimento teórico próprio sobre as relações de mercado e de troca entre organizações e sociedade. Cabe notar que a Economia não vem buscando trabalhos de Marketing sobre esses assuntos, ainda que possam ser do seu interesse.

Buscar as respostas para estes questionamentos significa também vislumbrar qual (ou quais) caminho(s) a produção científica de Marketing poderá seguir no seu futuro. Um destes caminhos seria focar na produção gerencial, isto é, buscando aplicar conhecimentos externos e rigor metodológico para atender aos problemas enfrentados pelas empresas na sua relação com mercados e consumidores. Neste rumo, a produção científica de Marketing focaria em atender basicamente à Administração, produzindo resultados empíricos relevantes para o planejamento estratégico das empresas, mas sem maiores preocupações em atingir um status científico mais elevado ou em desenvolver teorias puras.

Outro caminho, bem diferente, seria o de acentuar o desenvolvimento do Comportamento do Consumidor como uma disciplina autônoma - uma realidade cada vez mais perceptível nos EUA com o número crescente de periódicos dedicados apenas a este tema, mas ainda não evidente no Brasil. Esta opção implicaria em explorar os fenômenos de consumo em seu próprio direito, sem a necessidade de 
relacionar implicações gerenciais, aproximando-se, por exemplo, da produção da Psicologia e da Sociologia.

Além destes caminhos, existe ainda a opção de se esforçar na consolidação de teorias próprias do Marketing, buscando explicar, por exemplo, a troca (econômica) entre organizações e sociedade, isto é, tomando para si o mercado como objeto de estudo tal qual faz a Economia - deixando assim de entender o Marketing como uma função interna às empresas para vislumbrá-lo como um fenômeno maior do que elas e do âmbito da sociedade. Esta opção não significaria que o Marketing seria menos importante para o planejamento estratégico das empresas, podendo ocorrer até mesmo pelo contrário, como já defendeu Hunt (2002). Porém, esta opção certamente representa um desafio, dados os diversos obstáculos presentes para a geração de teoria na área (Yadav, 2010).

Naturalmente, os resultados desta análise bibliométrica não foram produzidos livres de certas limitações. Entre elas, a forma de levantamento dos dados aborda apenas os cinco principais periódicos de cada área e, desta forma, não abrange a possibilidade de que periódicos em tópicos especializados (mas de menor fator de impacto) poderiam ter interesse maior em Marketing e produzir mais citações. Assim, pode ter havido um viés na medida em que os periódicos abordados representam apenas uma parcela dos interesses das demais áreas. Além disso, apesar de considerar um período de quase seis anos, o estudo não analisa longitudinalmente a produção de Marketing. Por esta razão, pesquisas futuras poderiam ser elaboradas buscando comparar diferentes cortes de tempo, a fim de verificar a evolução das contribuições da área ao longo dos anos. Por fim, o processo de análise considerou não considerou as divisões existentes nas demais ciências sociais. Neste sentido, a investigação realizada poderia ser estendida considerando-se as subáreas da Administração (por exemplo, Gestão ou Relações Humanas), assim como das demais ciências (Psicologia Experimental, Psicologia Social, etc.). De qualquer maneira, os resultados apresentados já permitiram propor questionamentos que certamente poderão ser mais aprofundados em futuras investigações e lançar uma nova luz sobre os caminhos que a disciplina pretende seguir na sua relação com as demais ciências sociais.

\section{Referências}

Alba, J., Lynch, J., Weitz, B., Janiszewski, C., Lutz, R., Sawyer, A., \& Wood, S. (1997). Interactive home shopping: consumer, retailer, and manufacturer incentives to participate in electronic marketplaces. Journal of Marketing, 61(3), 38-55. doi: 10.2307/1251788

Anderson, M. H. (2006). How can we know what we think until we see what we said? A citation and citation context analysis of Karl Weick's the social psychology of organizing. Organization Studies, 27(11), 1675-1692. doi: 10.1177/0170840606068346

Anderson, P. F. (1983). Marketing, scientific progress, and scientific method. Journal of Marketing, 47(4), 18-31. doi: 10.2307/1251395

Armstrong, J. S., \& Overton, T. S. (1977). Estimating nonresponse bias in mail surveys. Journal of Marketing Research, 14(3), 396-402. doi: 10.2307/3150783

Backhaus, K., Lügger, K., \& Koch, M. (2011). The structure and evolution of business-to-business marketing: a citation and co-citation analysis. Industrial Marketing Management, 40(6), 940-951. doi: 10.1016/j.indmarman.2011.06.024

Bartels, R. (1988). The history of marketing thought. Columbus: Publishing Horizons.

Baumgartner, H. (2010). Bibliometric reflections on the history of consumer research. Journal of Consumer Psychology, 20(3), 233-238. doi: 10.1016/j.jcps.2010.06.002 
Baumgartner, H., \& Pieters, R. (2003). The structural influence of marketing journals: a citation analysis of the discipline and its subareas over time. Journal of Marketing, 67(2), 123-139. doi: 10.1509/jmkg.67.2.123.18610

Block, L. G., \& Keller, P. A. (1995). When to accentuate the negative: the effects of perceived efficacy and message framing on intentions to perform a health-related behavior. Journal of Marketing Research, 32(2), 192-203. doi: 10.2307/3152047

Brown, S. W., Webster, F. E., Jr., Steenkamp, J.-B. E. M., Wilkie, W. L., Sheth, J. N., Sisodia, R. S., Kerin, R. A., MacInnis, D. J., McAlister, L., Raju, J. S., Bauerly, R. J., Johnson, D. T., Singh, M., \& Staelin, R. (2005) Marketing renaissance: opportunities and imperatives for improving marketing thought, practice, and infrastructure. Journal of Marketing, 69(4), 1-25. doi: 10.1509/jmkg.2005.69.4.1

Castilhos, R. B. (2007, setembro). Apropriações da obra de Pierre Bourdieu no campo do marketing no Brasil. Anais do Encontro Nacional da Associação Nacional de Pós-Graduação e Pesquisa em Administração, Rio de Janeiro, RJ, Brasil, 31.

Churchill, G. A., Jr. (1979). A paradigm for developing better measures of marketing constructs. Journal of Marketing Research, 16(1), 64-73. doi: 10.2307/3150876

Clark, T., Key, T. M., Hodis, M., \& Rajaratnam, D. (2014). The intellectual ecology of mainstream marketing research: an inquiry into the place of marketing in the family of business disciplines. Journal of the Academy of Marketing Science, 42(3), 223-241. doi: 10.1007/s11747-013-0362-5

Cote, J. A., Leong, S. M., \& Cote, J. (1991). Assessing the influence of Journal of Consumer Research: a citation analysis. Journal of Consumer Research, 18(3), 402-410. doi: 10.1086/209269

Cote, J. A., Leong, S. M., \& Cote, J. (1992). Assessing the influence of marketing research on the social science literature. Marketing Letters, 3(3), 251-258. doi: 10.1007/BF00994133

Dalli, D., \& Galvagno, M. (2013, August). The literature on co-creation: bibliometric analysis and review. AMA Summer Marketing Educators' Conference Proceedings, Boston, MA, USA, 24.

Davis, D. F., Golicic, S. L., Boerstler, C. N., Choi, S., \& Oh, H. (2013). Does marketing research suffer from methods myopia? Journal of Business Research, 66(9), 1245-1250. doi: 10.1016/j.jbusres.2012.02.020

Day, G. S. (1994). The capabilities of market-driven organizations. Journal of Marketing, 58(4), 37-52. doi: $10.2307 / 1251915$

Day, G. S., \& Montgomery, D. B. (1999). Charting new directions for marketing. Journal of Marketing, 63(4), 3-13. doi: $10.2307 / 1252096$

Deighton, J., Romer, D., \& McQueen, J. (1989). Using drama to persuade. Journal of Consumer Research, 16(3), 335-343. doi: 10.1086/209219

Diamantopoulos, A., \& Winklhofer, H. M. (2001). Index construction with formative indicators: an alternative to scale development. Journal of Marketing Research, 38(2), 269-277. doi: 10.1509/jmkr.38.2.269.18845

Edell, J. A., \& Burke, M. C. (1987). The power of feelings in understanding advertising effects. Journal of Consumer Research, 14(3), 421-433. doi: 10.1086/209124

Escalas, J. E., \& Stern, B. B. (2003). Sympathy and empathy: emotional responses to advertising dramas. Journal of Consumer Research, 29(4), 566-578. doi: 10.1086/346251 
Faria, P. C. N., Oliveira, D. F., Lacerda, T. S., \& Lara, J. E. (2006, setembro). Mapeamento, análise e classificação dos trabalhos acadêmicos de Marketing nos Enanpads de 2000 a 2005. Anais do Encontro Nacional da Associação Nacional de Pós-Graduação e Pesquisa em Administração, Salvador, BA, Brasil, 30.

Fornell, C., \& Bookstein, F. L. (1982). Two structural equation models: LISREL and PLS applied to consumer exit-voice theory. Journal of Marketing Research, 19(4), 440-452. doi: $10.2307 / 3151718$

Fornell, C., \& Larcker, D. F. (1981). Evaluating structural equation models with unobservable variables and measurement error. Journal of Marketing Research, 18(1), 39-50. doi: 10.2307/3151312

Heide, J. B, \& John, G. (1992). Do norms matter in marketing relationships? Journal of Marketing, 56(2), 32-44. doi: 10.2307/1252040

Huber, J., Payne, J. W., \& Puto, C. (1982). Adding asymmetrically dominated alternatives: violations of regularity and the similarity hypothesis. Journal of Consumer Research, 9(1), 90-98. doi: $10.1086 / 208899$

Hunt, S. D. (2002). Foundations of marketing theory: toward a general theory of marketing. Armonk, NY: M. E. Sharpe.

Jarvis, C. B., MacKenzie, S. B., \& Podsakoff, P. M. (2003). A critical review of construct indicators and measurement model misspecification in marketing and consumer research. Journal of Consumer Research, 30(2), 199-218. doi: 10.1086/376806

Kevork, E. K., \& Vrechopoulos, A. P. (2009). CRM literature: conceptual and functional insights by keyword analysis. Marketing Intelligence and Planning, 27(1), 48-85. doi: $10.1108 / 02634500910928362$

Kim, J., \& McMillan, S. J. (2008). Evaluation of internet advertising research: a bibliometric analysis of citations from key sources. Journal of Advertising, 37(1), 99-112. doi: 10.2753/JOA00913367370108

Kotler, P., \& Levy, S. J. (1969). Broadening the concept of marketing. Journal of Marketing, 33(1), 1015. doi: $10.2307 / 1248740$

Kuhfeld, W. F., Tobias, R. D., \& Garratt, R. (1994). Efficient experimental design with marketing research applications. Journal of Marketing Research, 31(4), 545-557. doi: 10.2307/3151882

Leone, R. P., Robinson, L. M., Bragge, J., \& Somervuori, O. (2011). A citation and profiling analysis of pricing research from 1980 to 2010. Journal of Business Research, 65(7), 1010-1024. doi: 10.1016/j.jbusres.2011.04.007

Maheswaran, D., \& Meyers-Levy, J. (1990). The influence of message framing and issue involvement. Journal of Marketing Research, 27(3), 361-367. doi: 10.2307/3172593

Mazzon, J. A., \& Hernandez, J. M. C. (2013). Produção científica brasileira em marketing no período 2000-2009. Revista de Administração de Empresas, 53(1), 67-80. doi: 10.1590/S003475902013000100007

Mela, C. F., Roos, J., \& Deng, Y. (2013). Invited paper: a keyword history of marketing science. Marketing Science, 32(1), 8-18. doi: 10.1287/mksc.1120.0764

Morgan, R. M., \& Hunt, S. D. (1994). The commitment-trust theory of relationship marketing. Journal of Marketing, 58(3), 20-38. doi: 10.2307/1252308 
Morwitz, V. G., Greenleaf, E. A., \& Johnson, E. J. (1998). Divide and prosper: consumers' reactions to partitioned prices. Journal of Marketing Research, 35(4), 453-463. doi: 10.2307/3152164

Novak, T. P., Hoffman, D. L., \& Yung, Y.-F. (2000). Measuring the customer experience in online environments: a structural modeling approach. Marketing Science, 19(1), 22-42. doi: 10.1287/mksc.19.1.22.15184

Novemsky, N., Dhar, R., Schwarz, N., \& Simonson, I. (2007). Preference fluency in choice. Journal of Marketing Research, 44(3), 347-356. doi: 10.1509/jmkr.44.3.347

Pechmann, C., Zhao, G., Goldberg, M. E., \& Reibling, E. T. (2003). What to convey in antismoking advertisements for adolescents: the use of protection motivation theory to identify effective message themes. Journal of Marketing, 67(2), 1-18. doi: 10.1509/jmkg.67.2.1.18607

Pieters, R., \& Baumgartner, H. (2002). Who talks to whom? Intra- and interdisciplinary communication of economics journals. Journal of Economic Literature, 40(2), 483-509. doi: $10.1257 / 002205102320161348$

Pinto, M. R., \& Lara, J. E. (2007, setembro). A pesquisa na área do comportamento do consumidor: uma análise da produção acadêmica brasileira entre 1997 e 2006. Anais do Encontro Nacional da Associação Nacional de Pós-Graduação e Pesquisa em Administração, Rio de Janeiro, RJ, 31.

Reibstein, D. J., Day, G., \& Wind, J. (2009). Guest editorial: is marketing academia losing its way? Journal of Marketing, 73(4), 1-3. doi: 10.1509/jmkg.73.4.1

Rossi, C. A. V. (2008, maio). A utilidade da pesquisa do consumidor. Anais do Encontro de Marketing da ANPAD, Curitiba, PR, Brasil, 3.

Schwarz, N. (2004). Metacognitive experiences in consumer judgment and decision making. Journal of Consumer Psychology, 14(4), 332-348. doi: 10.1207/s15327663jcp1404_2

Sharma, S., Durand, R. M., \& Gur-Arie, O. (1981). Identification and analysis of moderator variables. Journal of Marketing Research, 18(3), 291-300. doi: 10.2307/3150970

Silveira, C. S., Esteves, P. S., \& Rossi, C. A. V. (2013). O que os outros pensam sobre marketing? A contribuição da disciplina para as ciências sociais. Revista Brasileira de Marketing, 12(2), 49-69. doi: 10.5585/remark.v12i2.2496

Soberon-Ferrer, H., \& Dardis, R. (1991). Determinants of household expenditures for services. Journal of Consumer Research, 17(4), 385-397. doi: 10.1086/208565

Stremersch, S., Verniers, I., \& Verhoef, P. C. (2007). The quest for citations: drivers of article impact. Journal of Marketing, 71(3), 171-193. doi: 10.1509/jmkg.71.3.171

Talukdar, D., Hariharan, V. G., \& Boo, C. (2011). Empirical regularity in academic research productivity patterns in marketing. International Journal of Research in Marketing, 28(3), 248257. doi: 10.1016/j.ijresmar.2011.03.003

Tellis, G. J., Chandy, R. K., \& Ackerman, D. S. (1999). In search of diversity: the record of major Marketing journals. Journal of Marketing Research, 36(1), 120-131. doi: 10.2307/3151920

Thaler, R. (1985). Mental accounting and consumer choice. Marketing Science, 4(3), 199-214. doi: 10.1287/mksc.4.3.199

Watts, D. J., \& Dodds, P. S. (2007). Influentials, networks, and public opinion formation. Journal of Consumer Research, 34(4), 441-458. doi: 10.1086/518527 
Webster, F. E., Jr., \& Lusch, R. F. (2013). Elevating marketing: marketing is dead! Long live marketing! Journal of the Academy of Marketing Science, 41(4), 389-399. doi: 10.1007/s11747-013-0331-z

Wilkie, W. L., \& Moore, E. S. (2003). Scholarly research in marketing: exploring the "4 eras" of thought development. Journal of Public Policy \& Marketing, 22(2), 116-146. doi: 10.1509/jppm.22.2.116.17639

Yadav, M. S. (2010). The decline of conceptual articles and implications for knowledge development. Journal of Marketing, 74(1), 1-19. doi: 10.1509/jmkg.74.1.1

Zaichkowsky, J. L. (1985). Measuring the involvement construct. Journal of Consumer Research, 12(3), 341-352. doi: 10.1086/208520

Zauberman, G., Kim, B. K., Malkoc, S. A., \& Bettman, J. R. (2009). Discounting time and time discounting: subjective time perception and intertemporal preferences. Journal of Marketing Research, 46(4), 543-556. doi: 10.1509/jmkr.46.4.543

\section{Dados dos Autores}

Renato Hübner Barcelos

Rua Washington Luiz, 855, Centro, 90010-460, Porto Alegre, RS, Brasil. E-mail: renatohubner@ gmail.com

Carlos Alberto Vargas Rossi

Rua Washington Luiz, 855, Centro, 90010-460, Porto Alegre, RS, Brasil. E-mail: cavrossi @ea.ufrgs.br 